\title{
Value-oriented Information Systems Design: The Concept of Potentials Modeling and its Application to Service-oriented Architectures
}

\author{
The value proposition of information technology (IT) is subject to a number of situational \\ context factors and cannot be easily assessed. The concept of potentials modeling proposed \\ in this paper seeks to extend existing methods of information modeling and to provide a \\ means for evaluating information systems design alternatives in a specific organizational \\ context. The approach is substantiated by the example of service-oriented architectures (SOA).
}

DOI 10.1007/s12599-009-0046-3

\section{The Authors}

Prof. Dr. Jan vom Brocke Christian Sonnenberg MSc Alexander Simons MSc University of Liechtenstein Hilti Chair of Business Process Management, Institute of Information Systems Fürst-Franz-Josef-Straße 21 9490 Vaduz

Principality of Liechtenstein \{jan.vom.brocke | christian. sonnenberg | alexander.simons\}@ hochschule.li

Received: 2008-09-02 Accepted: 2009-02-27 Accepted after three revisions by the editors of the special focus.

This article is also available in German in print and via http://www.wirtschaftsinformatik.de: vom Brocke J, SonnenbergC, Simons A (2009) Wertorientierte Gestaltung von Informationssystemen: Konzeption und Anwendung einer Potenzialmodellierung am Beispiel Serviceorientierter Architekturen. WIRTSCHAFTSINFORMATIK. doi: 10.1007/11576-009-0168-8.

\section{Introduction}

Today, it is probably common sense that information technology (IT) does not create value per se. Instead, an alignment of technical possibilities and economic interests, commonly discussed under the term "IT business alignment" (Henderson and Venkatraman 1993), is crucial. The discussion particularly focuses on the question of how the most efficient application of IT can be accomplished with regard to organizational requirements. It was particularly stimulated by the so-called "productivity paradox" (Brynjolfsson 1993) and subsequent studies on the value contribution of IT (Carr 2004). Today, however, the question is less whether IT contributes to corporate value creation, but rather how the IT value added can be realized (vom Brocke and Buddendick 2008 , p. 1). Nonetheless, preliminary work in the field does not provide entirely satisfying answers. This perception has also been acknowledged in recent studies showing that IT executives have a high demand for solutions for an IT business alignment (Luftman 2005; Luftman et al. 2006).

Consequently, there is a great need for methods enabling an analysis of the economic value of information systems design. The primary objective lies in justifying IT investments in a specific organizational context. Such a value assessment is of major importance nowadays, since the potential number of technology-induced design alternatives has significantly increased. Service-oriented architectures (SOA) provide a topical example for this perception (vom Brocke 2008). While system vendors propagate a new paradigm, particularly characterized by a huge number of alignment options between business and IT, there is still uncertainty whether - and to what extent - the adoption of SOA will prove beneficial in a specific organization. Given the possibility of selecting alternative services, SOA allows for a multitude of design options whose economic consequences can hardly be estimated in rational terms without methodical support.
This paper proposes an approach for assessing the economic value of information system design decisions by extending existing methods of information modeling (Frank 1999; Frank 2000, p. 339; Frank 2006, p. 1; Wand and Weber 2002). Therefore, the concept of "potentials modeling" is introduced, allowing for both a factual and a value-oriented specification of design alternatives. That being said, we set out to explore to what extent the economic potentials associated with information systems design can be considered in the modeling process. We particularly consider the perspective of an organization aimed at designing information systems of highest possible value. However, the results should also be relevant for system vendors and intermediaries.

The work described in this paper was carried out following a constructivist approach (Becker and Niehaves 2007, p. 202; Kasanen et al. 1993) and is based on a design-science oriented research process (March and Smith 1995). The structure of the paper can be summarized as follows: First, we clarify the scope of analysis and the underlying terminology (section 2.1). Next, we present selected results gained from a literature review in order to outline the relevance of our approach in the context of SOA (section 2.2). Subsequently, we introduce the concept of potentials modeling by proposing fundamental methodical components that are specified by means of reference meta-models (vom Brocke 2003, p. 85) (section 3). Using event-driven process chains (EPC) (Keller et al. 1992), an application example serves as an illustration of concept (section 4). The paper finally concludes with a discussion of the results (section 5) and an outlook on future research (section 6). 

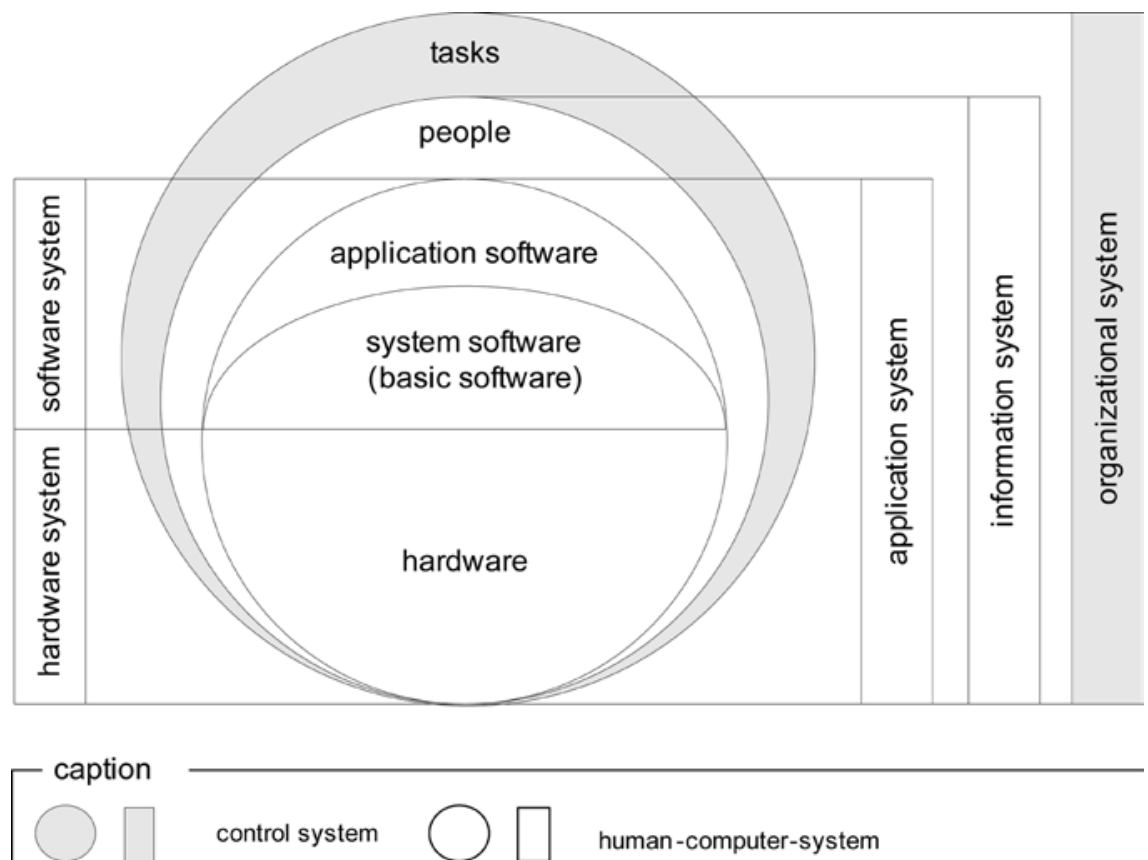

control system

human-computer-system

Fig. 1 Application, information and organizational systems (following Teubner 1999, p. 26)

\section{Research overview}

\subsection{Scope of analysis and terminology}

The value-oriented analysis of information systems design generally bears a challenge for all application domains. Nonetheless, there are definitely domain-specific requirements that have to be considered; this paper focuses on the concept of SOA. This is due to two reasons. Firstly, we address a topical and still emerging field in both information systems research and practice. Secondly, we assume structural analogies with regard to the initially and generally motivated problem and thus consider the results to be well suited for generalization.

Serving as a foundation for our approach, the terminology used in this paper is clarified first (Fig. 1).

Here, an information system is understood as a goal-oriented, socio-technical system serving the processing or the exchange of information (Davis and Olsen 1985; Ferstl and Sinz 1993, pp. 1 ff). Information can be defined as explicit knowledge, and knowledge as conceptions of the truth of statements (Teubner 1999, p. 17). The explication of knowledge is realized via supporting media on which information is prepared for the purpose of processing (exchanging) data (messages) (vom Brocke 2003, pp. 27 f). Information systems can be perceived as socio-technical systems, since not only software and hardware, but also humans are involved in information processing and exchange. In contrast, application systems are parts of information systems which are entirely executed automatically. Moreover, information systems are goal-oriented, as they serve the fulfillment of tasks. They are part of the company's organizational system which - following an instrumental conceptualization of the organization - describes how specific tasks need to be executed by the interplay of human, information and technology (Kosiol 1962, p. 18; Nordsieck 1955, p. 23).

The concept of SOA aims at assembling application systems from different subsystems which provide specific services and coupling them in a loose manner. Such a "loose coupling" means that subsystems are not only used for executing processes inside a single application system - instead, specific sub-systems of different processes are provided by means of a situational configuration of application systems (Leymann 2003, p. 20).

Fig. 2 illustrates the impact of SOA on information systems design (compared to the conventional situation without SOA).

The development of traditional application systems is based on assumptions about the processes being supported by and implemented in the systems' application layer (Buck-Emden 1999, pp. 115 ff). On the one hand, this offers the advantage of embedding the corporate process know-how within the systems. On the other hand, it limits the possibility of process change and adaptation (to be conducted in the system's development phase only). The concept of SOA is inspired by the idea of abolishing these restrictions. Therefore, process logic and process control are decoupled (Leymann 2003, p. 13; Schmidtmann 2005, p. 17). That way, processes can be (re-)designed according to situational requirements and, at the same time, selected application system services can be used for the execution of certain activities. A SOA infrastructure allows for both integrating existing systems as well as enabling the integration of new services (Dostal et al. 2005, p. 19; Leymann 2003, pp. $1 \mathrm{f}$; Woods and Mattern 2006, p. 104). Legacy systems can be integrated by using special services as so-called "wrappers" (Sneed and Sneed 2003, pp. 36 f) that offer their functionality via an enterprise service bus (ESB). As a result, the boundaries of an information system are determined by the individual process design and can be shifted dynamically in the course of process adaptations (Andresen et al. 2005, pp. 64 ff; Woods 2004, p. 23).

In conclusion, SOA particularly raises the question of the IT value proposition anew. The economic value of SOA adoptions often still remains unclear, since the, in many cases, rather euphoric expectations are insufficiently justified by profitability calculations. This perception has also been acknowledged in a recent hypecycle analysis by Gartner, positioning SOA in a phase of potentially "inflated expectations" (Gartner Inc 2005). Case studies shared by system vendors frequently report three-digit profitability ratios which further fuel these expectations (vom Brocke 2008 , p. 2). These studies are particularly misleading, since they cannot simply be transferred to other application contexts. It is likely that the economic potential of SOA is subject to a number of situational context factors that, moreover, vary considerably in different application scenarios. Therefore, concepts allowing for the evaluation of individual SOA design options are required. Methodical support, however, can hardly be found in prior literature - as outlined in the next subsection. 


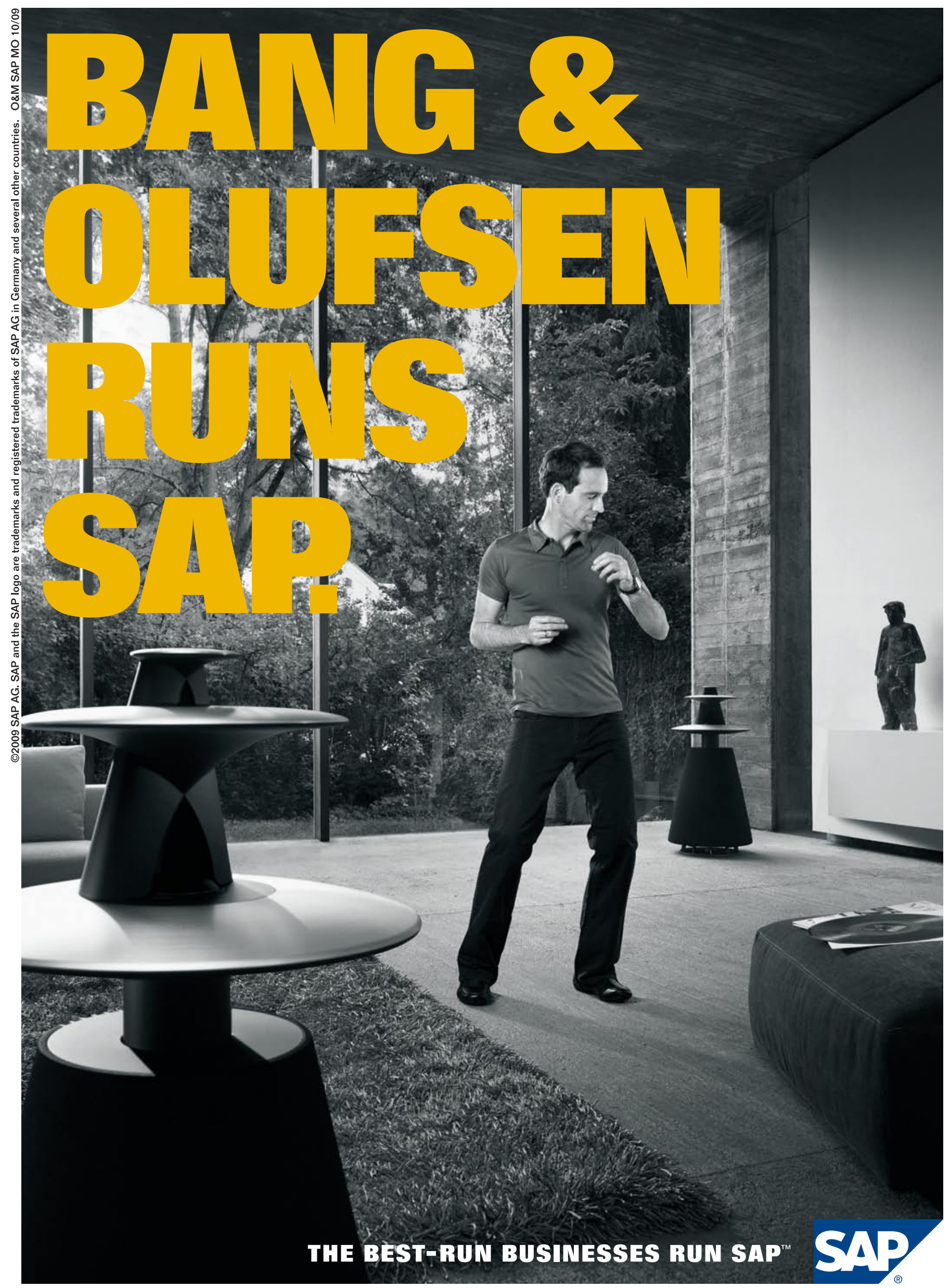




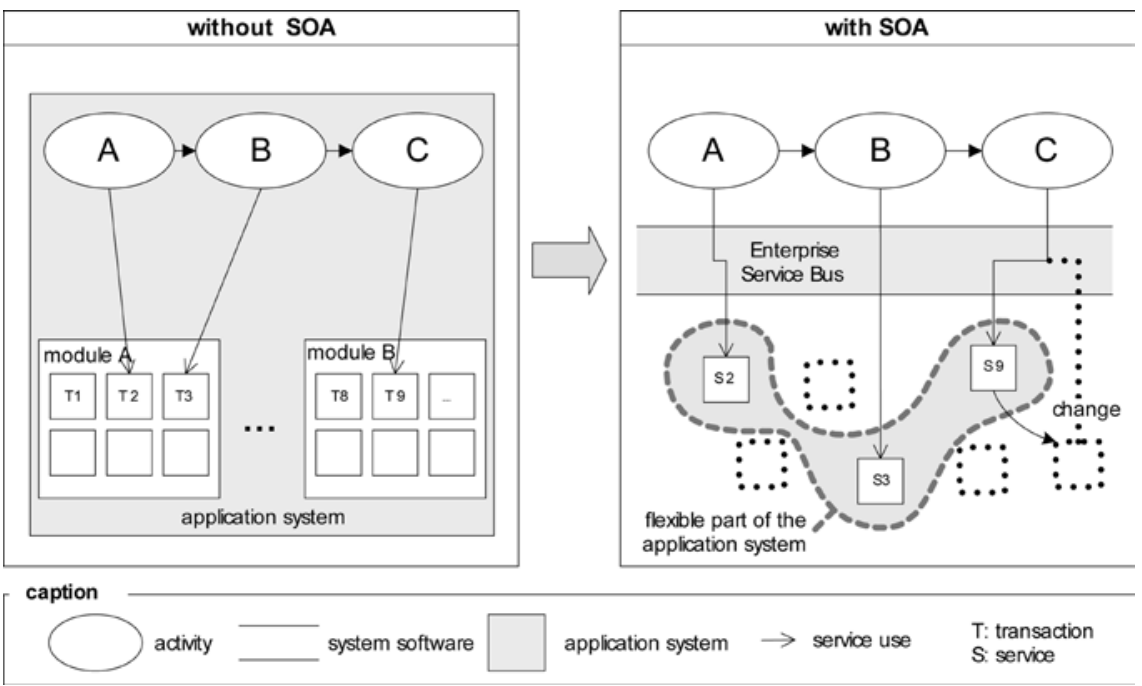

Fig. 2 The impact of SOA on information systems design (vom Brocke 2008, p. 13)

\subsection{Related work}

Research in the field is particularly characterized by works on the evaluation of IT investments (Brynjolfsson 1993; Hitt and Brynjolfsson 1996; Im et al. 2001; Mukhopadhyay et al. 1995; Porter and Millar 1985; Tam et al. 1998). These contributions, however, often remain too abstract to capture the plethora of alternatives in information systems design. Conversely, related work on more specific design problems often neglects the economic dimension. In the following, this is illustrated more precisely for the SOA domain.

Most contributions that focus on analyzing SOA aim at providing decision support for the choice of web services. These rather technically-oriented contributions often propose selection criteria for web services (Kalepu et al. 2003; Ran 2003; Zeng et al. 2003). Formal methods are put forward aiming at an ad-hoc selection of web services at process runtime on the basis of these criteria (Cardoso et al. 2004; Day and Deters 2004; Padovitz et al. 2003; Spahn et al. 2006, p. 2). For example, Lee and Park (2003) present an approach for selecting web services which takes into account operational requirements as well as the functional specifications of the web services.

Contributions with a more economic focus provide estimates on the macroeconomic impact of SOA (Dibbern et al. 2001; Hagel and Brown 2003; Löwer and Picot 2002). In addition, general potential benefits of deploying the new architectural concept are described (Erl 2005;
Krafzig et al. 2006; Woods 2003; Woods and Mattern 2006). Occasionally, total cost of ownership (TCO) and return on investment (ROI) calculations are proposed for selected application examples which, however, lack transferability (vom Brocke 2008). Only recently, a discussion of methodical requirements for evaluating SOA has begun. Examples include contributions focusing on success factors (Durst and Daum 2007), performance indicators (Fiedler and Seufert 2007) and profitability calculations (vom Brocke 2007a).

In conclusion, the outlined approaches represent fundamental preliminary works. However, so far, they are largely isolated from each other and, in particular, have not been associated with information systems modeling - as it is proposed by the concept of potentials modeling to be introduced in the following section. In order to develop a generic conceptualization of potentials modeling, we draw on prior work in the field of both value-driven design of service-oriented information systems (Thomas and vom Brocke 2009) as well as value-oriented process modeling (vom Brocke et al. 2008a) to illustrate our arguments.

\section{Introducing the potentials modeling approach}

\subsection{Overview}

The idea of potentials modeling lies in specifying and evaluating information systems design alternatives given in a particular development project. Here an information model is understood as a special type of model describing constituents of an information system (Frank 1999). A potentials model is neither to be confused with an as-is model, documenting the current situation, nor with a to-be model, representing the future situation to be finally implemented. Instead, a potentials model covers relevant design alternatives to be compared with each other in terms of their value proposition in a specific organizational situation. In terms of decision theory, an alternative represents one out of multiple exclusionary decision choices (Grob 2006, p. 6). In the course of a information systems (re-)design, thus, several potentials models are compared in order to finally identify the most beneficial alternative. Fig. 3 illustrates the conception.

The concept of potentials modeling distinguishes factual and value-oriented potentials: (1) The factual specification of design alternatives forms the foundation for further analysis. Considering the SOA example, this means, e. g., to capture alternative services for supporting individual functions - but also the various alternatives for business process redesign. (2) The economic consequences associated with the design alternatives are documented and consolidated within valueoriented potentials models (e. g. by means of financial measures). (3) On that basis, the alternatives can be compared and design decisions can successively be modified. (4) Concluding, such an evolutionary approach makes it possible to create, compare and modify potentials models until - from a decision maker's perspective a beneficial alternative has been identified. The latter finally represents the tobe model for the subsequent implementation.

In the following, the idea of modeling both factual and value-oriented potentials is described in more detail.

\subsection{Factual modeling of design potentials}

Compared to conventional information models, potentials models are characterized by optionality. They present "candidates" - or "alternatives" in terms of decision theory - for information systems design. Two general principles for the factual representation of potentials can be distinguished:

- Implicit representation: The set of design alternatives is specified within a 
Fig. 3 Evolutionary development of factual and value-oriented potentials models for finally identifying the to-be model of implementation

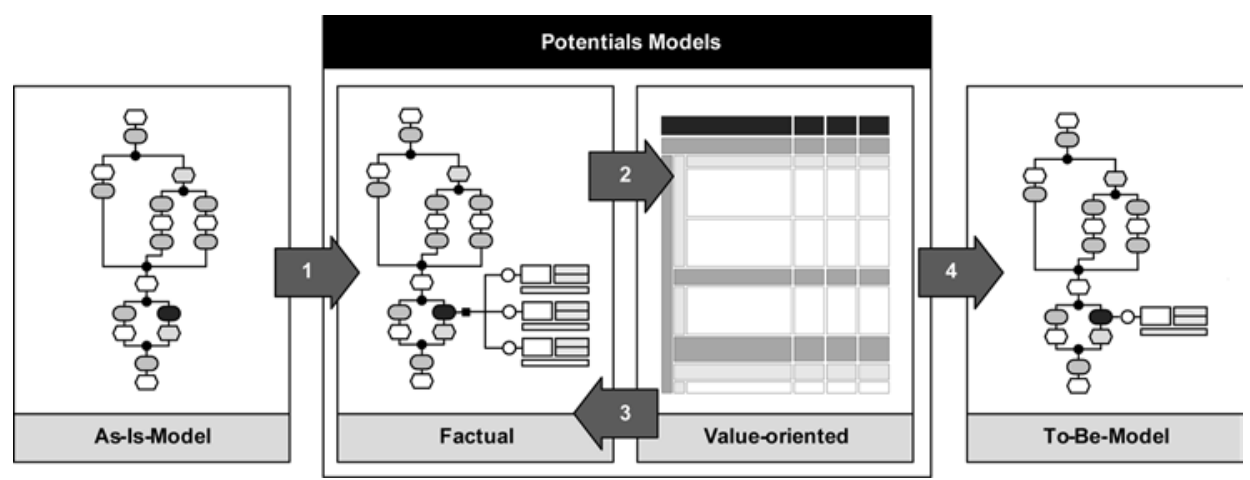

single model, thus requiring constructs for the representation of the alternatives as well as rules for managing possible dependencies.

- Explicit representation: Each single design alternative is specified in an explicit model. Optionality is expressed by the relationships between the models, which can be represented using a corresponding operator in the model system.

The choice of an either explicit or implicit representation is influenced by the number of alternatives as well as their heterogeneity. If, for instance, an outtasking decision referring to the selection of alternative services from several service providers (Reichmayr 2003, pp. $99 \mathrm{ff}$ ) is to be made, the economic benefits of an implicit representation come into effect. However, if a decision also causes changes in the organizational structure, as it is the case in process integration or reorganization initiatives (Linthicum 2000, p. 18), for the sake of a preferably clear presentation, an explicit model might be superior.

Potentials models contribute to both the documentation and evaluation of design alternatives, e. g. in the context of redesigning corporate organizational structures. This is why process modeling languages can be applied for the factual representation of design alternatives (an overview of fields of application of process modeling is given by Rosemann et al. 2005, pp. $51 \mathrm{ff}$ ). For leveraging benefits of reuse, it seems reasonable to apply modeling languages which have already been used in specific application domains for as-is modeling. Examples of wellestablished process modeling languages, already specified by means of metamodels, are the EPC (Rosemann 1996, pp. 122 f), petri nets (Baumgarten 1996, pp. $50 \mathrm{ff}$ ) and unified modeling language (UML) activity diagrams (Rumbaugh et al. 1998, pp. $81 \mathrm{ff}$ ). In particular the EPC is one of the most frequently used process modeling languages in both research and practice (Davies et al. 2006).

In the case of SOA, the representation of institutionalization alternatives in process models is particularly crucial. Therefore, constructs are requaried that allow for specifying processes at an activity, infrastructure and service level (vom Brocke 2007a). However, process modeling languages are typically comprised of constructs making it possible to describe processes at the activity level only (e. g., events, functions and control flow operators). The conceptual modeling of potentials in the context of SOA, therefore, requires an extension of existing modeling languages by means of constructs for specifying services and infrastructures. Whereas services perform a specific functional task by making use of a certain set of resources, infrastructure elements represent the specific requirements necessary for integration. At least partly, these constructs are determined by both the specifics of individual services and the application context. The optionality given by SOA is then captured by representing services as alternative institutionalizations for single activities. The basic relationships are visualized in a reference meta-model (Fig. 4).

The displayed entity relationship model (ERM) (Chen 1976) outlines the constructs relevant for the factual representation of potentials in the context of SOA. The figure shows that in order to execute a certain activity, alternative services can be used (activity-service-rel.). Services may also require specific infrastructure elements (infrastructure-service-rel.). The configuration of a service portfolio necessitates the selection of a specific service for each process activity (service selection). Within this context, an aggregation of all process activities is crucial, including a consolidation of the requirements on the infrastructure layer.
In the following, we build upon the results explained so far and introduce the concept of value-oriented potentials modeling.

\subsection{Value-oriented modeling of design potentials}

An evaluation of information system design alternatives requires a clarification of the underlying value concept. In microeconomics, the value of a good represents its importance for satisfying one's needs (Stavenhagen 1998, p. 235). A distinction is made between the utility value of a product or service and its exchange value (Ott 1975, p. 116). Business administration often focuses on the exchange or market value, which is described in monetary value measures (e.g. the market price, see Ott 1975, p. 116). Both short-term (e. g. revenues and expenditures, costs) as well as long-term value measures (based on in-payments and out-payments) are applied. In the context of value-based management, long-term and "futureoriented" value measures play a vital role (Copeland et al. 2002, pp. 86 ff). Long-term value measures are largely based on the discounted cash flow (DCF) method; examples for related indicators are the economic value added (EVA), the economic profit or the cash flow return on investment (CFROI) (Copeland et al. 2002, p. 88). Existing approaches to measure the value of IT primarily draw on short-term value measures (e. g., infrastructure costs), as the long-term economic consequences are often not clearly quantifiable (Im et al. 2001). However, the economic value of IT investments can also be analyzed on the basis of business processes. As a result, the latter become subject to internal evaluations (Ray et al. 2007). Business processes can be evaluated with the activity-based costing method (Horváth and Mayer 1998 , p. 59). In doing so, however, the 

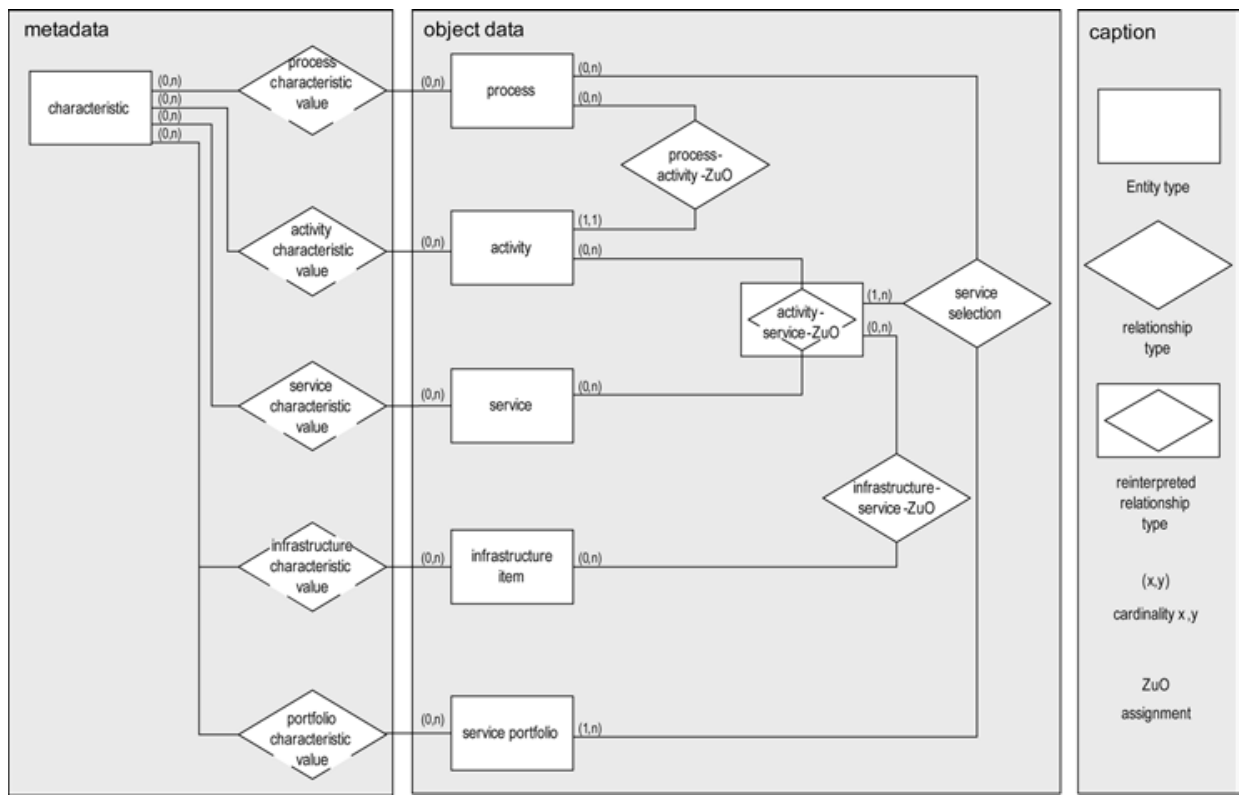

Fig. 4 Reference meta-model in ER notation (Chen 1976) for representing factual design alternatives in the context of a SOA-driven process design (Thomas and vom Brocke 2009) problem of reporting short-term and "historical" measures remains. Only recently, approaches have been suggested to evaluate business processes based on long-term value measures (vom Brocke 2007b; vom Brocke and Lindner 2005; vom Brocke et al. 2008a; Thomas and vom Brocke 2009).

In conclusion, the evaluation of information systems design alternatives may take different valuation approaches as a basis. This paper follows a financial, process-oriented approach to uncover the long-term economic consequences of design decisions. Such a valuation approach requires a comprehensive examination in both factual as well as temporal terms (vom Brocke 2007a). Factual decisions not only refer to the selection of the "correct" system - the increasing adaptation possibilities also require numerous decisions concerning the "correct" adaptation and migration of systems. Within this context, a dynamic analysis of design decisions has to be employed, covering several periods of the planning horizon. Overall, from a financial perspective, the payments in the whole planning horizon related to specific design decisions are to be analyzed. These include original payments directly related to an investment as well as indirect, derivative payments especially those resulting from interest and tax effects as well as depreciation modalities (Grob 2006, pp. 104 f).

The basic constructs for assessing the original payments in the context of SOA are illustrated in the reference meta-model shown in Fig. 5.
The figure shows that the payments at the activity, infrastructure and service level must be summed up for certain service portfolio configurations. For this purpose, the locally documented values have to be aggregated according to the specific business process structure. Methods of business process analysis and simulation can be applied (Schmidt 2002, pp. 97 ff). Such methods should particularly allow for the consideration of different probabilities for entering process branches. As a result, a series of payments can be reported that represents the monetary consequences of a specific process variant. This series of payments forms the link for calculating derivative payments as well as financial ratios by means of established capital budgeting methods. Examples are the ROI and TCO that can be calculated based on the specific data situation of an organization.

The approach outlined here is illustrated by means of an example in the following section.

\section{Example of application}

As an example of application, in the following we design the fictional case of a medium-sized logistics company specialized in the parcel delivery sector.

In some divisions, the company applies a web-based enterprise portal, which is intended to be expanded to support all business processes - similar to the model of enterprise resource planning (ERP) systems - in the long term. As a first step of expansion, it is planned to integrate the route planning process into the portal. The company distinguishes two planning types, namely: detailed plans and ad-hoc plans. To determine the planning type, orders are prioritized due to time constraints. That being said, supply contracts showing a high priority strictly have to be planned in a detailed manner. However, if the available processing time is not sufficient for detailed planning, ad-hoc plans are created. Ad-hoc plans increase the risk of determining inefficient routes and often lead to missed deadlines and penalties as well as to an inefficient use of the vehicle fleet.

So far, the main process steps of the route planning process have been carried out manually. However, the considerable complexity of manual route planning led to a large number of ad-hoc plans in the past - particularly in the case of high priority orders. By integrating the route planning process into the portal, the company expects a lower error rate, a better adherence to delivery dates and a more efficient utilization of available resources. All in all, the design potential of the portal integration thus can be seen in an increase of both the planning capacity and quality by decreasing the manual planning efforts of the dispatchers. Technically, the development of the enterprise portal is supposed to be based on a SOA. Different design alternatives have to be investigated for the realization:

1. GlobalRoutePlanning: IT solution enabling both the development of route plans via an online interface and their 
storage in the company's database. The application of the service requires the transmission of supply contracts, fleet capacity, order priorities, as well as delivery addresses and dates. Employing this solution means to entirely outsource the creation of route plans.

2. GeoDataForLogistics: In-house solution that enriches existing internal routing rules and customer data with external route information. The latter are delivered via a map service specifically tailored to transportation logistics companies. On the one hand, this service may significantly reduce the input necessary for route planning. On the other hand, it also requires the self-development of multiple data services (wrappers).

3. IntelligentRouting: Web service enabling the creation of complete route plans in comparison to service (1), however, only for German-speaking countries. Generally, the timeliness of the geographical data tends to be higher for this service (as also construction sites or road closures are taken into account, for example). This promises to further improve the planning quality.

In the following, the design alternatives given in the example will be subject to a closer analysis based on the concept of potentials modeling. Therefore, the factual potentials of the three alternatives are to be captured first (Fig. 6).

The model shows an excerpt from the route planning process and specifies the design alternatives in an implicit manner (see Section 3.2). Moreover, the model reveals the different requirements on the infrastructure level coming along with the integration of the three services into the process (acquisition and maintenance of an ESB, interface implementation as well as self-development). In the example, the decision of whether or not a service is implemented is of local impact only, since there are no structural or institutional dependencies to other processes (or parts of processes). The economic consequences associated with the implementation of the three design alternatives may finally be disclosed by a value-oriented analysis. Therefore, particularly the number of process executions and the services' inherent risk of both failures and errors have to be taken into account particulary.

In conclusion, the model displayed in Fig. 6 shows the factual design possibilities given in the example. In order to finally identify a to-be model, a compari-

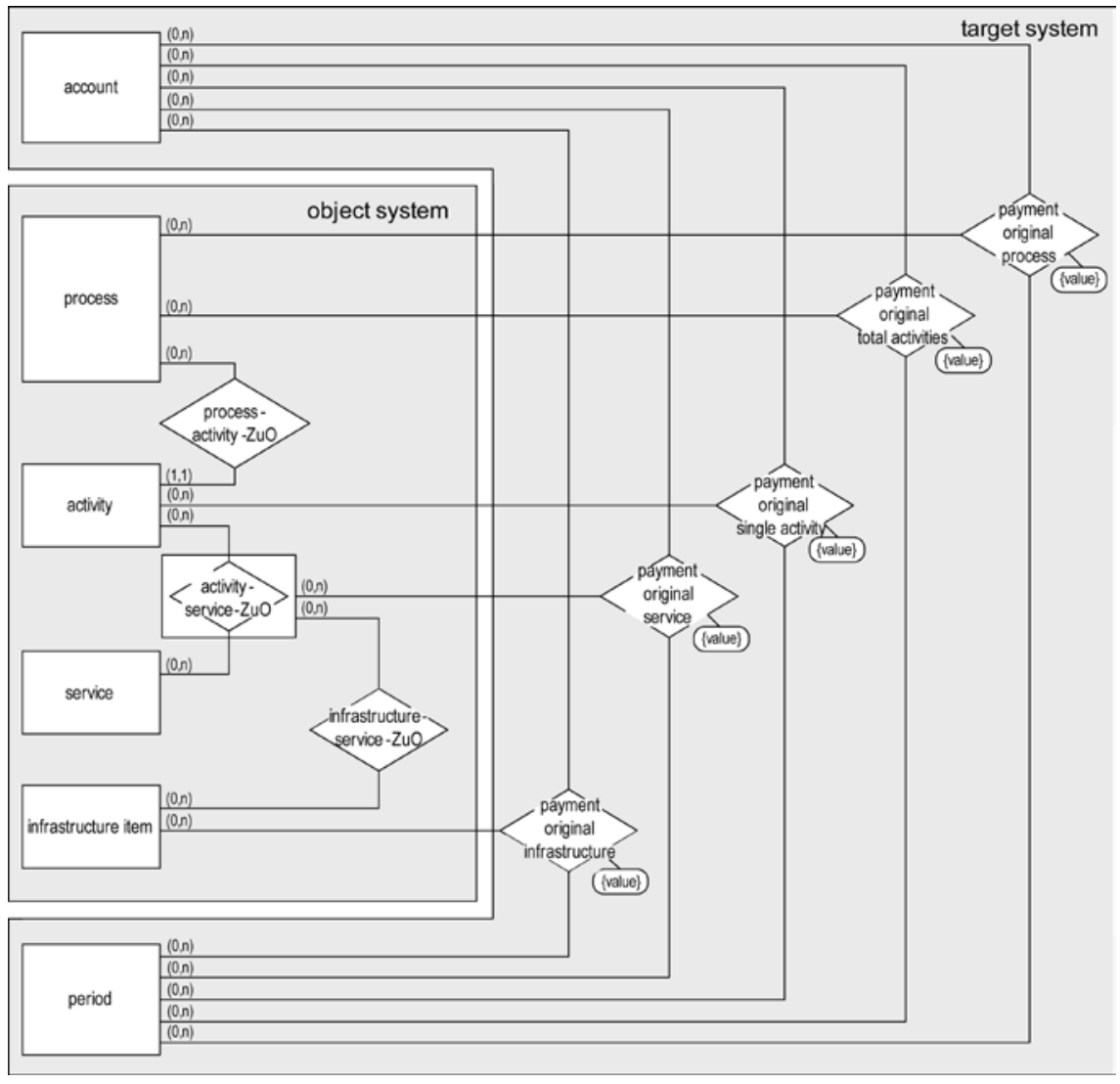

Fig. 5 Reference meta-model in ER notation (Chen 1976) for representing value-oriented design alternatives in the context of a SOA-driven process design (Thomas and vom Brocke 2009)

son of the three alternatives based on the idea of value-oriented potentials modeling can be conducted. The calculation of the financial consequences is summarized in Fig. 7 (focusing on the IntelligentRouting web service).

As mentioned above, in the example the design decisions are of local impact only. As a result, a partial examination (based on a differential calculation) can be conducted for capturing the original payments. Therefore, it is necessary to examine what additional payments - compared to maintaining the status quo (as-is) - are associated with the three design alternatives (to-be). Relevant payments are identified on the activity, infrastructure and service level and presented more precisely in the following:

- Activity level: Generally, the application of the services in the route planning process promises both a greater number of possible detailed plans $(p D P)$ and a higher quality of realized detailed plans $(r D P)$. Firstly, it is assumed that the processing time $(P T)$ of the activity "create detailed plan" can be reduced from ten to five minutes. Secondly, an improved error rate (ER) can be expected when creating the detailed plans - in the case of the web service IntelligentRouting from twenty to three percent, for example. Taking into account the available capacity $(C A)$ of 1,825 working hours, the number of process executions $(P E)$ of 18,250 and the default risk $(D R)$ of the web service of three percent, savings in period 1 mount up to $22,356 €$ for IntelligentRouting (compared to continuing the status quo). This calculation is based on the assumption that creating a detailed plan implies a benefit of $2,50 €$ on average compared to ad-hoc planning.

- Infrastructure level: The application of the IntelligentRouting web service requires the implementation of an ESB solution. The example assumes that the company follows an incremental adoption strategy (Hagel and Brown 2003). Therefore, both the capital expenditures of 25,000 $€$ and the subsequent periodical payments for maintenance 


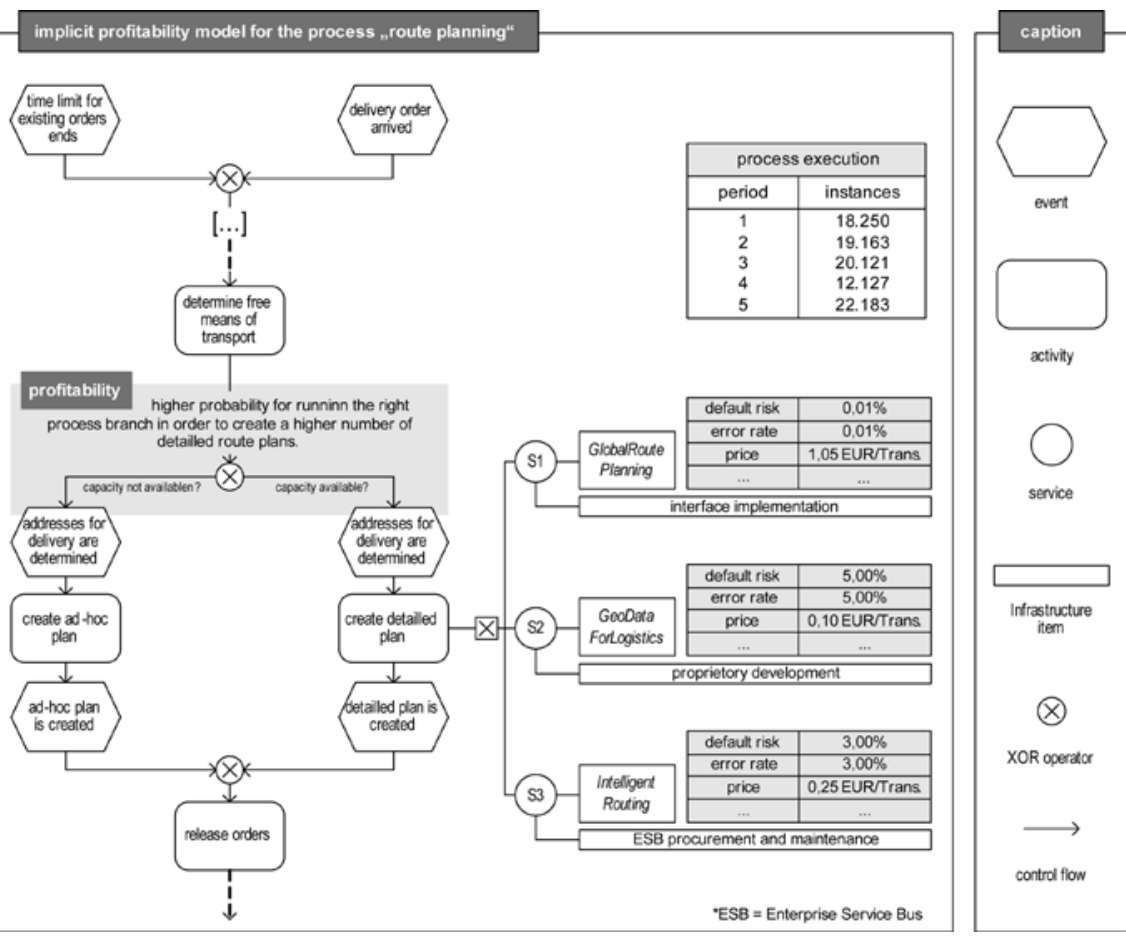

Fig. 6 Factual potentials model of the route planning process (following an implicit representation of the design alternatives)

and adaptation can entirely be imputed to the alternative. Referring to the outtasking case (GlobalRoutePlanning), the payments at the infrastructure level are significantly lower. In contrast, the relatively high implementation effort (wrappers) coming along with implementing the GeoDataForLogistics alternative, causes additional infrastructure payments.

- Service level: The calculation of the original payments on the service level for the IntelligentRouting web service follows a transaction-based pricing model with a cost rate of $0,25 €$ per transaction. Generally, the payments for each period are calculated based on the expected execution frequency of the activity "create detailed plan" $\left(\approx r D P_{t o-b e}\right)$. In period 1 , for example, service payments for IntelligentRouting mount up to $4,426 €$ (given 17,702 realized detailed plans). In contrast, an outsourcing of the route planning process would - at a lower default risk result in correspondingly higher payments of $19,161 €$ (at a given cost rate of $1,05 €$ per transaction). Finally, the calculation of the service payments for GeoDataForLogistics also requires the consideration of internal resource cost rates.
Next, the payments need to be aggregated for decision support. For each alternative, a series of payments has to be determined (serving as the highest aggregation of the original payments). On that basis, the derivative payments have to be calculated. For evaluating the alternatives' profitability, financial plans can be employed according to the VOFI method (Visualization of Financial Implications) (Grob 2006). VOFI allows for the calculation of both the payment inflows and outflows associated with a series of payments resulting from the alternatives' various investment, credit and fiscal conditions. The VOFI balance of the last period represents the final value of the investment in a particular service. In the above example, the terminal value of the investment in the reorganization process using the IntelligentRouting (GlobalRoutePlanning; GeoDataForLogistics) web service accounts for $30,379 €(25,424 €, 26,235 €)$. Compared with the opportunity's terminal value of $11,425 €$ (at a $6 \%$ credit interest rate), the implementation of the services seems to be value-adding as a matter of principle. However, the investment in the IntelligentRouting alternative generates the highest terminal value (the ROI of this alternative is $14.63 \%)$.

\section{Discussion}

The potentials modeling approach seeks to identify the economic consequences of decisions concerning the selection and adaptation of information systems. Picking up on the concept of SOA, we have shown how methods of information modeling can be extended to allow for an enterprise-specific value assessment.

The monetary value measures as calculated in the example may support decision making. However, by no means do we argue for grounding investment decisions solely on a single target value. Instead, the concept of potentials modeling in fact allows for analyzing target value variations as a function of different planning scenarios. Within the example, a critical process frequency of 35 executions per day $(12,775$ per period) exists, leading to the SOA investment not proving beneficial. In addition to such sensitivity analyses, the entire spectrum of decision theory can be used to gain further insights into the economic consequences of information systems design.

The approach described here aims to reuse best practices. This applies to both methods of process modeling as well as to methods of profitability accounting. Undoubtedly, one challenge lies in identifying and analyzing the relevant payments in individual application cases. In practice, such an analysis can cause significant planning efforts. However, it is likely that possibilities for reuse exist here and thus seems to be promising for information systems research to investigate certain application domains with regard to relevant payment types. In analogy to the concept of reference modeling, reusable templates for accounting systems could be developed for a whole class of applications. In the example, we created a basic structure for capturing payments related to the adoption of SOA by differentiating payments on an infrastructural, service and activity level. Other templates have already been developed, e. g. for enterprise architectures (vom Brocke et al. 2008b), virtual communities (vom Brocke et al. 2008b) and enterprise content management systems (vom Brocke et al. 2009).

\section{Summary and outlook}

This work can be seen as a plea for valueoriented information systems design and 


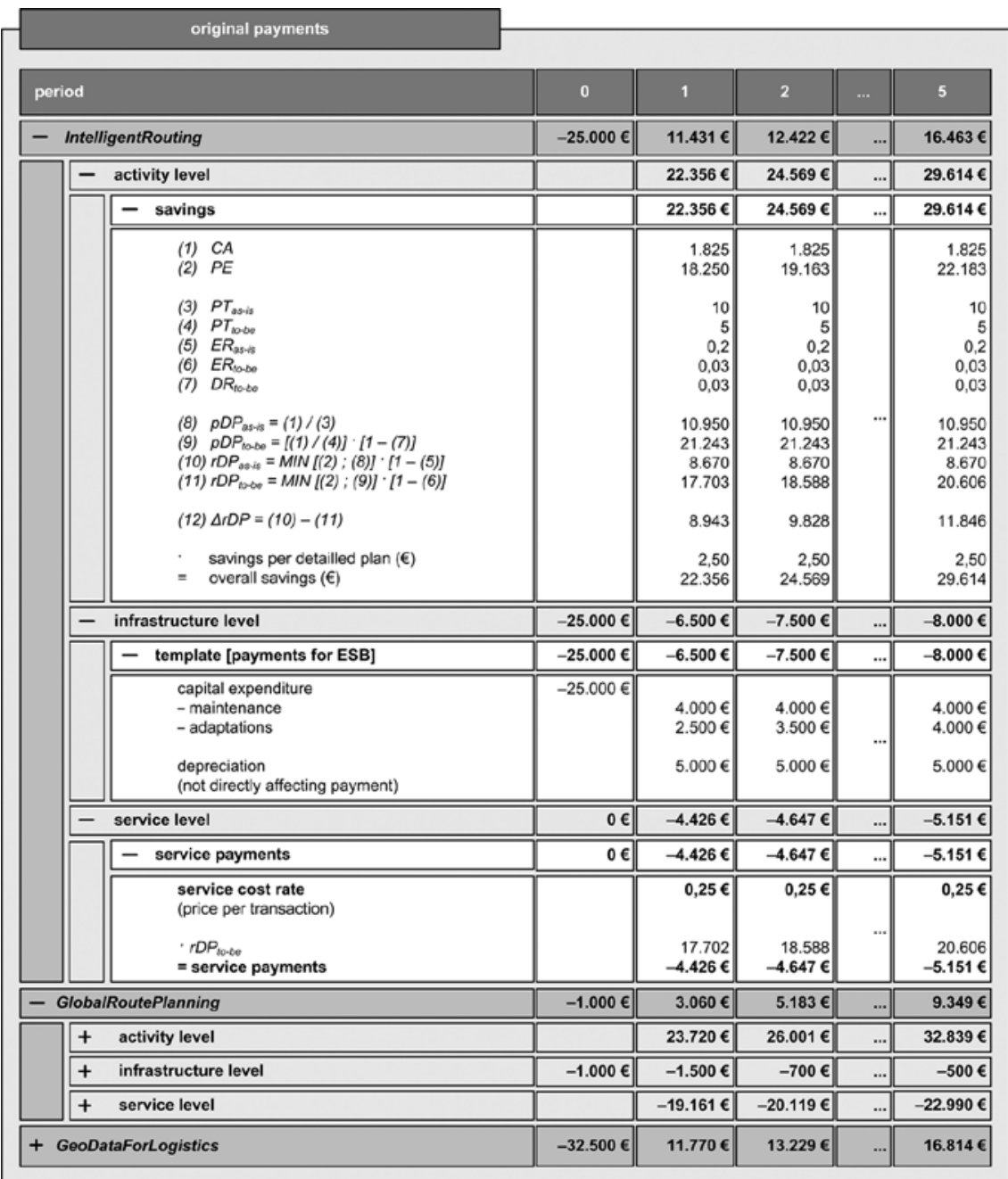

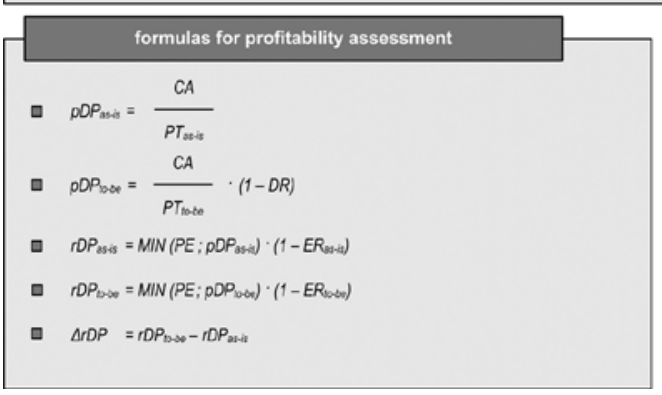

\begin{tabular}{|lll}
\hline \multicolumn{2}{|c}{ legend } & \\
\cline { 1 - 2 } & $C A$ & capacity (hour/period) \\
$\square$ & $P E$ & process execution (number) \\
$\square$ & $P T$ & processing time (min.) \\
$\square$ & $E R$ & error rate (\%) \\
$\square$ & $D R$ & default risk (\%) \\
$\square$ & $D D P$ & possible detailed plans (number) \\
$\square$ & IDP & realized detaled plans (number) \\
\hline
\end{tabular}

Fig. 7 Calculation of original payments associated with the SOA adoption

introduces the concept of potentials modeling. Given the increasing number of design alternatives, it can be assumed that such a modeling approach will become even more important in the future. Moreover, the work shows an application of the potentials modeling approach in the context of SOA. On the one hand, this focus was defined with regard to the given research design. On the other hand, we simultaneously also considered a very topical issue in information systems research.

It has to be noted that further evaluations are pending. This applies to both the analysis of additional application areas and to further modeling techniques. In addition, the cost-benefit ratio of potentials modeling has to be examined more precisely. Probably, there is a trade-off between the soundness and the simplicity of the proposed concept. The challenge definitely lies in developing methods for value-oriented modeling that are situationally adaptable and, thus, applicable to use cases of varying complexity. Moreover, we consider further dimensions of value to be necessary in the method construction. All in all, the primary objective of research in this particular field lies in providing decision makers with a "cockpit," enabling them to analyze the economic consequences of their actions in the context of value-oriented information systems design.

\section{References}

Andresen K, Gronau N, Schmid S (2005) Ableitung von IT-Strategien durch Bestimmung der notwendigen Wandlungsfähigkeit von Informationssystemarchitekturen. In: Ferstl OK, Sinz EJ, Eckert S, Isselhorst T (eds) Wirtschaftsinformatik 2005. eEconomy, eGovernment, eSociety. Physica-Verlag, Heidelberg

Baumgarten B (ed) (1996) Petri-Netze. Grundlagen und Anwendungen. Spektrum, Heidelberg

Becker J, Niehaves B (2007) Epistemological perspectives on IS research: a framework for analysing and systematizing epistemological assumptions. Information Systems Journal (17):197-214

Brynjolfsson E (1993) The productivity paradox of information technology. Communications of the ACM 36(12):66-77

Buck-Emden R (1999) Die Technologie des SAP R3 Systems. Addison-Wesley, Bonn

Cardoso J, Sheth AP, Miller JA, Arnold J, Kochut K (2004) Quality of service for workflows and web service processes. Journal of Web Semantics (3)1:281-308

Carr N (ed) (2004) Does IT matter? Information technology and the corrosion of competitive advantage. Harvard Business School, Harvard Chen PPS (1976) The Entity-Relationship Model. Toward a unified view of data. ACM Transactions on Database Systems 1(1):9-36

Copeland TE, Koller T, Murrin J (2002) Unternehmenswert - Methoden und Strategien für eine Wertorientierte Unternehmensführung. Campus Fachbuch, Frankfurt

Davies I, Green P, Rosemann M, Indulska M, Gallo $S$ (2006) How do practitioners use conceptual modelling in practice? Data \& Knowledge Engineering 58(3):358-380

Davis GB, Olsen MH (1985) Management information systems: Conceptual foundations, structure, and development. McGraw-Hill, New York Day J, Deters R (2004) Selecting the best web service. In: Proceedings of the 2004 conference of the centre for advanced studies on collaborative research, Markham

Dibbern J, Güttler W, Heinzl A (2001) Die Theorie der Unternehmung als Erklärungsansatz für das selektive Outsourcing der Informationsverarbeitung. Entwicklung eines theoretischen Bezugsrahmens. Zeitschrift für Betriebswirtschaft (71):675-699

Dostal W, Jeckle M, Melzer I, Zengler B (2005) Serviceorientierte Architekturen mit Web Services. Konzepte, Standards, Praxis. Spektrum Akademischer Verlag, München

Durst M, Daum M (2007) Erfolgsfaktoren serviceorientierter Architekturen. HMD - Praxis der Wirtschaftsinformatik 43(253):18-27

Erl T (2005) Service-oriented architecture: con- 


\section{Abstract}

Jan vom Brocke, Christian Sonnenberg, Alexander Simons

\section{Value-oriented Information Systems Design: The Concept of Potentials Modeling and its Application to Service-oriented Architectures}

Companies are increasingly confronted with the question of whether or not the adoption of information technologies (IT) turns out to be a profitable venture. Thus, there is a great need for methods which allow for both the analysis and evaluation of the economic value of IT investments. In this paper we introduce the concept of potentials modeling which integrates a value-oriented perspective into information modeling. More specifically, we set out to explore the economic value of service-oriented architectures (SOA). The practicability of our approach is illustrated on the basis of a simplified application example. It is hoped that this paper will make a contribution to the ongoing discussion of IT value and stimulates further research in the field of value-oriented information systems (IS).

Keywords: Potentials modeling, Information modeling, Service-oriented architectures (SOA), Value cepts, technology, and design. Prentice-Hall, Upper Saddle River

Ferstl OK, Sinz EJ (1993) Der Modellierungsansatz des Semantischen Objektmodells (SOM). In: Bamberger Beiträge zur Wirtschaftsinformatik, Arbeitsbericht Nr. 18, Bamberg

Fiedler M, Seufert A (2007) Der SOA-Entscheidungsprozess und Ansatzpunkte für ROI-Betrachtungen. HMD - Praxis der Wirtschaftsinformatik 43(253):28-36

Frank U (1999) Conceptual modeling as the core of the information systems discipline - perspectives and epistemological challenges. In: Proceedings of the $5^{\text {th }}$ Americas conference on information systems, Milwaukee

Frank U (2000) Modelle als Evaluationsobjekt: Einführung und Grundlegung. In: Heinrich LJ (ed) Evaluation und Evaluationsforschung in der Wirtschaftsinformatik: Handbuch für Praxis, Lehre und Forschung. Oldenbourg, München, pp 339-352

Frank U (2006) Towards a pluralistic conception of research methods in information systems research. In: Adelsberger $\mathrm{H}$ et al. (eds) ICB Research Reports, Arbeitsbericht Nr. 7, Essen

Gartner Inc (2005) Hype cycle for application development 2005. http://www.gartner.com/ DisplayDocument?doc_cd=127755. Accessed 2008-12-12

Grob HL (2006) Einführung in die Investitionsrechnung. Vahlen, München

Hagel JI, Brown S (2003) The agile dance of architectures - Reframing IT enabled business opportunities. http://www.johnhagel.com/paper_agiledance.pdf. Accessed 2008-12-08

Henderson JC, Venkatraman N (1993) Strategic alignment: Leveraging information technology for transforming organisations. IBM Systems Journal 32(1):272-284

Hitt LM, Brynjolfsson E (1996) Productivity, business profitability, and consumer surplus: three different measures of information technology value. MIS Quarterly 20(2):121-142

Horváth P, Mayer R (1998) Konzeption und Entwicklungen der Prozesskostenrechnung. In: Männel W (ed) Prozesskostenrechnung. Bedeutung - Methoden - Branchenerfahrungen Softwarelösungen. Gabler, Wiesbaden

Im KS, Dow KE, Grover V (2001) A reexamination of IT investment and the market value of the firm - an event study methodology. Information Systems Research 12(1):103-117

Kalepu S, Krishnaswamy S, Loke SW (2003) Verity: A QoS metric for selecting web services and providers. In: Proceedings of the $4^{\text {th }}$ international conference on web information systems engineering (WISE), WISE Workshops, Rom

Kasanen E, Lukka K, Siitonen A (1993): The constructive approach in management accounting research. Journal of Management Accounting Research (5):243-264

Keller G, Nüttgens M, Scheer AW (1992) Semantische Prozessmodellierung auf der Grundlage "Ereignisgesteuerter Prozessketten (EPK)". In: Scheer AW (ed) Arbeitsbericht Nr. 89 des Instituts für Wirtschaftsinformatik der Universität des Saarlandes, Saarbrücken

Kosiol E (1962) Organisation der Unternehmung. Gabler, Wiesbaden

Krafzig D, Banke K, Slama D (2006) Enterprise
SOA: service-oriented architecture best practices. Prentice-Hall, Upper Saddle River

Lee J, Park MS (2003) Integration and composition of web service-based business processes. Journal of Computer Information Systems (24):82-92

Leymann F (2003) Web services: Distributed applications without limits. In: Weikum G, Schöning H, Rahm E (eds) BTW 2003, Datenbanksysteme für Business, Technologie und Web, Tagungsband der 10. BTW-Konferenz. Springer, Leipzig, pp 2-23

Linthicum DS (2000) Enterprise application integration. Addison-Wesley, Boston

Löwer UM, Picot A (2002) Web Services - Technologie-Hype oder Strategie-Faktor? Industrie Management 17(3):20-25

Luftman JN (2005) Key issues for IT executives 2004. MIS Quarterly Executive 4(2):269-286

Luftman JN, Kempaiah R, Nash E (2006) Key issues for IT executives 2005. MIS Quarterly Executive 5(2):81-99

March ST, Smith GF (1995) Design and natural science research on information technology. Decision Support Systems 15(4):251-266

Mukhopadhyay T, Kekre S, Kalathur S (1995) Business value of information technology: A study of electronic data interchange. MIS Quarterly 19(2):137-156

Nordsieck F (1955) Rationalisierung der Betriebsorganisation. Poeschel, Stuttgart

Ott A E (1975) Kompendium der Volkswirtschaftslehre, Bd. 1. Vandenhoeck \& Ruprecht, Göttingen

Padovitz P, Krishnaswamy S, Loke SW (2003) Towards efficient selection of web services. In: Proceedings of the web services and agent-based engineering, Melbourne

Porter ME, Millar VE (1985) How information gives you competitive advantage. Harvard Business Review 63(4):149-160

Ran S (2003) A model for web services discovery with QoS. ACM SIGecom Exchanges 4(1):1-10

Ray G, Muhanna WA, Barney J B (2007) The role of shared it-business understanding. Communications of the ACM 50(12):87-91

Reichmayr C (2003) Collaboration und WebServices: Architekturen, Portale, Techniken und Beispiele. Springer, Berlin

Rosemann M (1996) Komplexitätsmanagement in Prozessmodellen: Methodenspezifische Gestaltungsempfehlungen für die Informationsmodellierung. Gabler, Wiesbaden

Rosemann M, Schwegmann A, Delfmann P (2005) Vorbereitung der Prozessmodellierung. In: Becker J, Kugeler M, Rosemann M (eds) Prozessmanagement. Ein Leitfaden zur prozessorientierten Organisationsgestaltung. Springer, Heidelberg

Rumbaugh JE, Jacobson I, Booch G (1998) The Unified Modeling Language reference manual. Addison-Wesley, Amsterdam

Schmidt G (2002) Prozessmanagement - Modelle und Methoden. Springer, Berlin

Schmidtmann V (2005) Web Services-basierte Referenzarchitektur für Enterprise Application Integration. Wissenschaftlicher Verlag, Berlin

Sneed HM, Sneed SH (2003) Web-basierte Systemintegration. Vieweg+Teubner, Wiesbaden

Spahn M, Berbner R, Heckmann O, Steinmetz R 
(2006) Ein heuristisches Optimierungsverfahren zur dienstgütebasierten Komposition von Web-Service-Workflows. Technical Report, Multimedia Communications Lab, TU Darmstadt

Stavenhagen G (1998) Geschichte der Wirtschaftstheorie. Vandenhoeck \& Ruprecht, Göttingen

Tam KY, Moinzadeh K, Berke E (1998) The impact of information technology investments on firm performance and evaluation: evidence from newly industrialized economies. Information Systems Research 9(1):85-98

Teubner RA (1999) Organisations- und Informationssystemgestaltung. Theoretische Grundlagen und integrierte Methoden. Deutscher Universitäts-Verlag, Wiesbaden

Thomas O, vom Brocke J (2009) A value-driven approach to the design service-oriented information systems - making use of conceptual models. Information Systems and e-Business Management (ISeB), Accepted 2009-02-02

vom Brocke J (2003) Referenzmodellierung: Gestaltung und Verteilung von Konstruktionsprozessen. Logos, Berlin

vom Brocke J (2007a) Wirtschaftlichkeit Serviceorientierter Architekturen - Management und Controlling von Prozessen als Service Portfolios. HMD - Praxis der Wirtschaftsinformatik 43(253):84-94

vom Brocke J (2007b) Service portfolio measurement. Evaluating financial performance of service-oriented business processes. International Journal of Web Services Research 4(2):1-32

vom Brocke J (2008) Serviceorientierte Architekturen: Management und Controlling von Geschäftsprozessen. Vahlen, München

vom Brocke J, Buddendick C (2008) Alignment Controlling - Der Beitrag einer wertorientierten Prozessgestaltung. In: Hofmann GR, Alm W (eds) Business-IT Alignment - Trends im Software und Servicemarkt. Tagungsband zur Teilkonferenz im Rahmen der Multikonferenz Wirtschaftsinformatik (MKWI), München vom Brocke J, Lindner M (2005) Service portfolio measurement. A framework for evaluating the financial consequences of out-tasking decisions. In: Proceedings of the $2^{\text {nd }}$ international conference on service oriented computing, New York

vom Brocke J, Mendling J, Recker J (2008a) Valueoriented process modelling. Towards a financial perspective on business process redesign. In: Proceedings of the $14^{\text {th }}$ Americas conference on information systems Toronto

vom Brocke J, Sonnenberg C, Lattemann C, Stieglitz S (2008b) Economics of virtual communities - the case of the Berlin stock exchange. In: Proceedings of the $14^{\text {th }}$ Americas conference on information systems, Toronto

vom Brocke J, Sonnenberg C, Thurnher B, Müller B (2008c) Wertorientierte Gestaltung von Unternehmensarchitekturen. HMD - Praxis der Wirtschaftsinformatik 47(262):78-88

vom Brocke J, Simons A, Sonnenberg C, Agostini $P$, Zardini A (2009) Value assessment of enterprise content management systems: A processoriented approach. In: D'Atri A, Saccà D (eds) Information systems: People, organizations, institutions, and technologies. Springer, Heidelberg
Wand Y, Weber R (2002) Information systems and conceptual modeling - a research agenda. Information Systems Research 13(4):363-376

Woods D (2003) Enterprise services architecture. O'Reilly, Beijing

Woods D (2004) Enterprise services architecture, Galileo Press, Bonn

Woods D, Mattern T (2006) Enterprise SOA: designing IT for business innovation. O'Reilly, Beijing

Zeng L, Benatallah B, Dumas M, Kalagnanam J, Sheng QZ (2003) Quality driven web services composition. In: Proceedings of the $12^{\text {th }}$ international conference on world wide web, Budapest 